\title{
Photoelectric recorder for measuring deformations of buildings and hydraulic facilities
}

\author{
Nematjon Zaxidov ${ }^{1}$, Shoakbar Shoyusupov ${ }^{2}$, Dilnoza Pulatova ${ }^{1}$, Shahzod Rahmatillayev ${ }^{1}$, \\ and Doniyor Gafurov ${ }^{1}$ \\ ${ }^{1}$ Named after I. Karimov Tashkent State Technical University, Tashkent, Uzbekistan \\ ${ }^{2}$ Tashkent Institute of Irrigation and Agricultural Mechanization Engineers, Tashkent, Uzbekistan
}

\begin{abstract}
The article discusses the issue of improving the accuracy and efficiency of geodetic measurements by scanning a laser beam into a plane and a photoelectric recorder of deviations from a given plane, in which a cZ-shaped photo recorder with three photosensors is used as a photosensor, combined at the output with three fiber-optic nodes and connected to an electronic circuit with three counters. A variant of using solar photovoltaic cells installed on the surface of a photoelectric recorder is proposed.
\end{abstract}

\section{Introduction}

During the construction and operation of industrial facilities, transport, hydrotechnical (HPP) and other structures, the main tasks of engineering and applied geodesy are the breakdown of axes, control of the installation of building structures in the design position, monitoring of precipitation and deformations, alignment of technological equipment, etc.

Increasing requirements for increasing the accuracy of equipment installation and automation of technological processes have necessitated the development of perfect methods and means of engineering and geodetic work, the use of special laser devices in combination with photoelectric recorders of the beam position in space, with a horizontally or vertically oriented light plane (by rotating the rotating laser beam or other methods of refraction or scattering into a plane) when controlling the layout, executive shooting, red lines.

It is especially important to use modern measuring instruments in seismically active zones, where the time factor is decisive because of which high requirements are imposed on the reliability and safety of buildings and structures, including hydraulic engineering, and, accordingly, the requirements for methods and means of geodetic control over their operation, including continuous monitoring [1-3].

The main direction of the development of engineering and geodetic measurements is developing and implementing methods and tools using special laser geodetic devices.

A significant drawback of visual devices, the impossibility of monitoring the position of the structures mounted by the installers themselves, requires the presence of an observer from a long distance, which reduces the efficiency, reliability, and accuracy of the measurement process, and requires the participation of additional personnel [4, 5].

To date, various foreign-made laser devices are used, such as "Rotolite", LIST, SKP-1 
for planning control, LAG-4 (MIIGAIK) in versions, Russian-made, Nivemat 2003K, Germany, etc. designed to perform various types of geodetic measurements [6-9].

\section{Methods}

To increase the efficiency, accuracy and level of automation of the process of alignment measurements, executive survey, control of planning, control of installation of structures, and other types of geodetic works, a version of a photoelectric recorder (FR) has been developed in which instead of solid or composite photodetectors (FP), fiber-optic optical bundles. The development is aimed at improving the "Photoelectric device for measuring linear dimensions" [10,11].

\section{Results and Discussion}

Based on the analysis of existing photoelectric and optoelectronic analyzers, photorecording means, the general disadvantages of the latest devices are the limited range, the complexity of the mechanical part and the manufacturing technology, high cost and energy consumption. A phased array design has been developed in which a photosensor and fiber optics are combined, which provides not only high efficiency and accuracy of measurements but also a decrease in the PA mass and an increase in the measurement range in the absence of mechanical elements and scanning parts, a drive (electric motor), which made it possible to reduce power consumption and the cost of the device $[12,13]$.

The main disadvantage of photoelectric analyzers in which the photolinear and compositional-linear ones are used, considered in Table 1, is the limited registration accuracy due to the inhomogeneity of the photosensitive part - zero drift along the entire length of the photolinear depending on the temperature gradient, power supply voltage, illumination, angle of incidence of the laser beam, etc. parameters, which is used in the technical solution, although it provides high efficiency of information retrieval measurements relative to the plane of rotation of the laser radiation $[14,15]$.

A distinctive feature of the device is the absence of moving elements and mechanical assemblies in it.

The displacement relative to the laser plane is determined by the formula

$$
S=l \cdot\left(n_{1} / n_{2}\right)
$$

where: $l$ is the known distance between photo receivers 1 and $3 ; \mathrm{n}_{1}, \mathrm{n}_{2}$ - readings of indicators of photodetectors 1.2 and 1.3.

The device includes a square plate 1 (Fig. 1), in which two parallel ones are made, and between them, narrow targets 2, 3, 4 are diagonally located (in Figure 1. They are shown enlarged), in which fiber- optical bundles 5, the other part of the bundles is connected to the photosensitive parts of photodetectors $6,7,8$. The size (area) of the receiving part of the PD is determined as follows: if the slot width is $0.5 \mathrm{~mm}$ and the length is $200 \mathrm{~mm}$, then the PD area should be $0.5 \mathrm{~mm} \times 200 \mathrm{~mm}=100 \mathrm{~mm}^{2}$, that is, it can have the dimensions of the photosensitive part $10 \mathrm{~mm} \times 10 \mathrm{~mm}$ or $8 \mathrm{~mm} \times 13 \mathrm{~mm}$, etc. In contrast to the prototype, the limited size of the PD has a much lower dependence on the dark current J, noise level, etc.

Fiber optic bundles do not need to be stacked in order as they are required to receive only the total energy of the laser beam.

If the FP has a round surface of the sensitive part, then the FP radius can be defined as: 


$$
R=\sqrt{\frac{10^{2} \mathrm{~mm}}{3: 14}} \approx 6 \mathrm{~mm} \text { diameter } \varnothing 12 \mathrm{~mm}
$$

It can be 2 parallel connected photodiodes FD24K, the area of the sensitive part is 78 $\mathrm{mm}^{2}$, or FD7K, etc.


Fig. 1. Layout diagram of fiber-optic bundles of FP: a) location of the slits (frontal view), b) view from the back side.

The work of the FR is no different from the prototype; the number of pulses $n, U, N$ is also recorded (Figure 2).

The main requirement when laying fiber-optic bundles is that the input ends should be perpendicular to the housing 1 and lie on the same line [16].

The dimensions of the phased array slots can be reduced to 0.1-0.2 mm, while photodiodes with a sensitivity area of up to $20-40 \mathrm{~mm}^{2}$ can be used. Due to the high concentration of the laser beam, the amplitude of the photodiode signals decreases insignificantly and does not in any way affect the measurement accuracy.

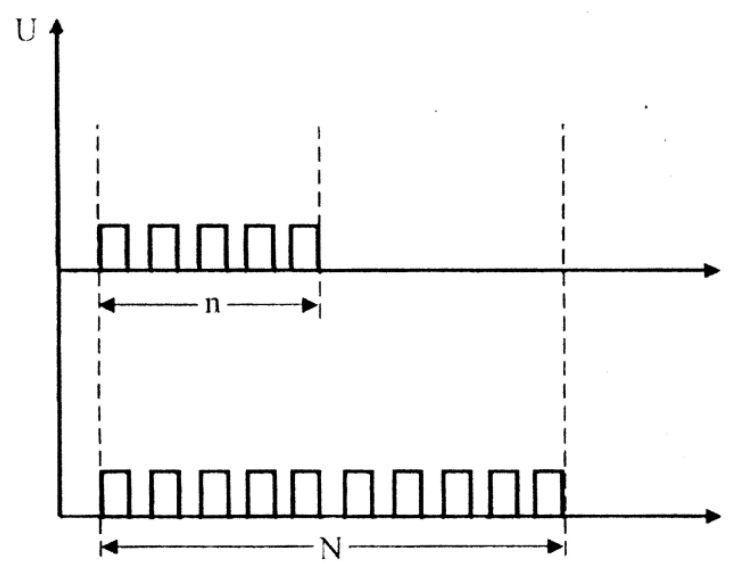

Fig. 2. Time-pulse schedule of the FR.

To obtain the objective accuracy of the FR measurements, a mock-up sample was made (Figure 4), using which, according to a certain method, the analysis and study of the accuracy of registration of displacements relative to the reference rotating laser beam were carried out.

The main source of error when registering a phased array laser beam is the instability of 
the power source. To prevent this factor, the power supply of the electronic circuit is supplied through a voltage converter, assembled according to the circuit of an asymmetric multivibrator (or according to the blocking generator circuit) [17], which converts direct current into alternating current, and then through a rectifier again into direct voltage. This makes it possible, firstly, to use the minimum number of galvanic cells ( 2 cells instead of 6 cells) and thereby reduce the dimensions and weight of the PD, the cost of purchasing (galvanic cells), and secondly, to obtain a relatively high voltage to power the PD (37 V) and, due to the increased (artificially) voltage, ensure stabilization using an electronic voltage stabilizer. The block diagram of the voltage converter connection is shown in Fig. 3 (only one channel is shown).

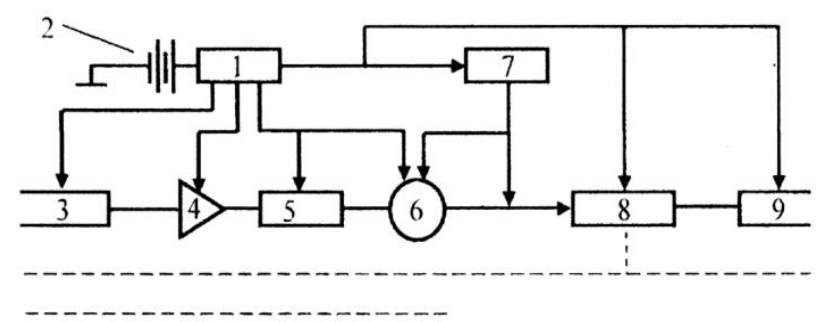

Fig. 3. Block diagram of connecting a voltage converter to separate blocks and units of the FR: 1 is voltage converter; 2 is power supply; 3 is FP; 4 is amplifier; 5 is trigger; 6 is electronic key, 7 is generator; 8 is electr. counter; 9 is indicator.

The stabilized voltage is supplied to FP-3, amplifier 4, trigger 5, electronic key 6 and crystal oscillator 7, and commemorative voltages are supplied to counter 8 and indicator 9 , where high stabilization is not required.

Considering that the $\mathrm{Z}$-shaped photo recorder has a significant free area $\mathrm{S}_{1}$ relative to the occupied area $S_{2}$ of the holes for photosensitive elements with the end parts of fiber optics with a ratio of about $\frac{s_{2}}{s_{1}} \approx 90 \%$, low power consumption $\mathrm{V}=5 \mathrm{~V}, I=70 \mathrm{~mA}, \mathrm{P}=$ 0.35 at the use of MOS microcircuits, CMOS structures with liquid crystal seven-segment indicators, as a power source it is proposed to use solar photovoltaic cells made of polycrystalline or amorphous silicon, which generates sufficient electricity from background lighting (even in cloudy weather) together with a Li-ion battery, which has a high specific energy capacity [18-24].

The proposed device works in conjunction with a unit for sweeping a laser beam into a plane. The sweeping methods have received the greatest application, including Rotolite, Leserfics, USA, Geoplane 300, Sweden and others.

Based on the analysis, a working model of a device for scanning a laser beam into a plane was made, in which the method of rotating a reflective prism by $90^{\circ}$. 


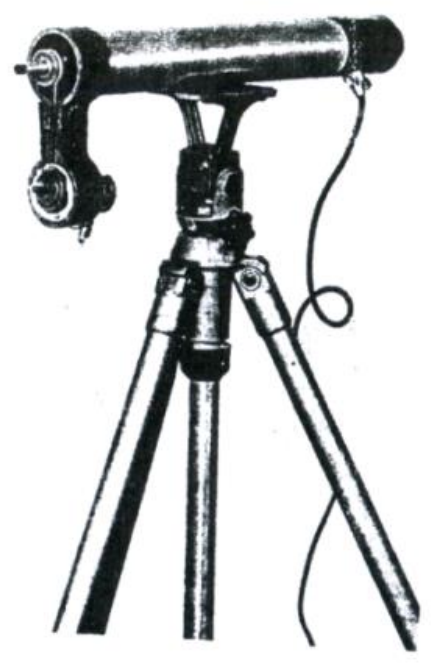

Fig. 4. Layout of the scanning unit (360) of the laser beam

\section{Conclusions}

Unlike stationary reference laser lines, the proposed device can be used to measure at any point in the laser plane.

The proposed device can also be used in alignment work, which simplifies the process of orientation of photoelectric registration and takes measurements at several points of the laser plane.

\section{Acknowledgements}

The study was supported by Tashkent State Technical University and Tashkent Institute of Irrigation and Agricultural Mechanization Engineers

\section{References}

1. Bolshakov V.D., Levchuk G.G. Reference book of a surveyor 2, pp. 360-372, (1985)

2. Gauf M. Electronic theodolites and tacheometers, Per. from Czech, pp. 15-13, (1978)

3. Eliseev S.V. Geodetic instruments and devices, Ed. 3rd, (1973)

4. Yambaev Kh.K., High-precision alignment measurements, pp. 115-164, (1978)

5. Zatsarinny A.V. Automation of high-precision engineering and geodetic measurements, p. 247, (1976)

6. Yambaev Kh.K., Special devices for engineering and geodetic works, p. 267, (1990)

7. Kamen H. "Electronic methods of measurements in geodesy" will be translated. pp. 70-115, Moscow, (1982)

8. Magyari B., Elements of Optoelectronics and Photoelectric Automation, per.svenger., pp. 83-110, Moscow, (1979),

9. Zakaznova N.M. Applied optics, Mechanical Engineering, pp. 128-132, (1988) 
10. Zakhidov N.M. SU No. 1670403 "Photoelectric device for measuring deviations, Application. 12.12.1988, publ. 1991, BI No. 30G01B21 / 00, (1991)

11. Zakhidov N.M. SU No. 1474466 "Photoelectric device for measuring linear dimensions", publ. 1989, BI No. 15G01B21 / 00, (1989)

12. Zakhidov N.M. Optoelectronic device for object orientation relative to the radiation source. Pos. dec. VNIGPE by application No. 4642462 G01B21/20

13. US Patent No. 756828. Reference plane setting device;

14. Katys G.P. Visual information processing, Mechanical Engineering, pp. 98-107, (1990)

15. Markova E.V, Maslak A.A, Randomization and statistical inference, pp. 89-120, Moscow, Finance and Statistics, (1986)

16. Treister R., Mayo J. 44 Power Supplies for Electronic Devices, translated from English, Moskva, Energoatomizdat, pp. 231-256, (1990)

17. Saitov E.B., Toshov J.B., Pulatov A.O., Botirov B.M., Kurbanov Yu.M. Networked interactive solar panels over the roof photovoltaic system (PVS) and its cost analysis at Tashkent state technical University, RSES 2020, E3S Web of Conferences 216, 01133 (2020)

18. Sapaev I., Saitov E., Zoxidov N., Kamanov B. Matlab-model of a solar photovoltaic station integrated with a local electrical network, Materials Science and Engineering, 883(1), 012116, (2020)

19. Toshov J., Saitov E. Portable autonomous solar power plant for individual use. E3S Web of Conferences 139 01087, (2019), doi: 10.1088/1757-899X / $883 / 1 / 012116$

20. Bakhadyrkhanov M.K., Valiev S.A., Zikrillaev N.F., Saitov, E.B., Tachilin, S.A. Silicon photovoltaic cells with clusters of nickel atoms, Applied Solar Energy 52 (4), pp. 278-281, (2016)

21. Zikrillayev N., Saitov E. Silicon materials the future of photovoltaics, Monograph - LAP LAMBERT Academic Publishing, (2019)

22. Shoyusupov Sh., Rakhmatullaev Sh., Shoyusupov Sh. Investigation of the transient characteristics of s-diodes based on silicon compensated by vanadium, International Conference on Enerdetics, Civil and Agricultural Engineering Tashkent, (2020)

23. Denmuhammadiev A.M., Shoyusupov Sh.A., ChullievY.E. Low-power solar stations on dam surfaces of reserrvoirs. International Scientific and Technical Conference, Construction Mechanics, Hydraulics and Waer Resources Engineering, Tashkent, (2020) 